\title{
Variation in growth patterns of Marsh Harrier Circus aeruginosus nestlings: effects of hatching order, nestling subperiod, brood size and weather conditions
}

\author{
Urszula Zaremba $^{1}$ [D $\cdot$ Artur Golawski $^{1} \cdot$ Zbigniew Kasprzykowski $^{1}$
}

Received: 5 February 2021 / Revised: 30 December 2021 / Accepted: 24 January 2022 / Published online: 18 February 2022

(c) The Author(s) 2022

\begin{abstract}
Post-natal growth has long-term consequences for survival and fitness in birds and is subject to strong directional selection. Highly variable patterns of nestling development are influenced by an array of extrinsic and intrinsic factors. This study analysed the impacts of hatching order, nestling subperiod, brood size and weather conditions, all of which could influence the growth rate of Marsh Harrier Circus aeruginosus nestlings. It was conducted over a period of 6 years, during which measurements of 173 nestlings from 66 nests were made at fishpond complexes in eastern Poland. Relative growth rates (RGR) were calculated on the basis of tarsus and wing lengths during two subperiods of nestling development. Linear mixed models showed that the hatching order and nestling subperiod influenced nestling growth, whereas brood size did not affect wing or tarsus relative growth rates. The effect of hatching order differed between the two traits and between subperiods. Marginal nestlings in broods of five exhibited poor wing growth and perished before fledging. In contrast to wing growth, tarsus growth rates were similar in all the siblings in the first subperiod. During the second developmental subperiod, the growth rates of both locomotor traits exhibited the same pattern, i.e., higher values in the later-hatched chicks than in the earlier ones. Precipitation, but not temperature, had a negative impact on growth in the second subperiod. Our results show a variation in growth patterns between nestmates, which was the most evident in the rate of wing growth. The study enhances our understanding of brood reduction and cainism in birds of prey.
\end{abstract}

Keywords Growth rate · Post-hatching growth · Brood reduction · Sibling competition · Growth strategy · Wing growth, Tarsus growth, Raptor

\section{Zusammenfassung}

Unterschiedliche Wachstumsmuster von Nestlingen der Rohrweihe Circus aeruginosus: Auswirkungen von Schlüpfreihenfolge, Entwicklungsphase, Brutgröße und Wetterbedingungen

Das postnatale Wachstum hat langfristige Auswirkungen auf das Überleben und die Fitness von Vögeln und unterliegt einer starken gerichteten Selektion. Die sehr unterschiedlichen Entwicklungsmuster der Nestlinge werden von einer Reihe äußerer und interner Faktoren beeinflusst. In der vorliegenden Untersuchung wurden die möglichen Auswirkungen der Reihenfolge des Schlüpfens, der Entwicklungsphase im Nest, der Brutgröße und der Witterungsbedingungen analysiert, die alle einen Einfluss auf die Wachstumsrate der Nestlinge der Rohrweihe Circus aeruginosus haben könnten. Die Untersuchung lief über einen Zeitraum von sechs Jahren, in denen 173 Nestlinge aus 66 Nestern in Fischteichanlagen in Ostpolen gemessen wurden. Anhand von Tarsen- und Flügellängen wurden relative Wachstumsraten (RGR) während zweier Entwicklungsphasen im Nest berechnet. Lineare, gemischte Modelle zeigten, dass die Reihenfolge des Schlüpfens und die Entwicklungsphase im

Communicated by O. Krüger.

Urszula Zaremba

ula.zaremba@gmail.com

1 Faculty of Exact and Natural Sciences, Siedlce

University of Natural Sciences and Humanities, Prusa 14,

08-110 Siedlce, Poland 
Nest das Wachstum der Nestlinge beeinflussten, wohingegen die Brutgröße keinen Einfluss auf die relativen Wachstumsraten der Flügel oder Tarsen hatte. Die Auswirkung der Reihenfolge des Schlüpfens unterschied sich zwischen diesen beiden Merkmalen und zwischen den beiden Entwicklungsphasen im Nest. In Fünferbruten zeigten die Nestlinge am Nestrand ein schlechtes Flügelwachstum und starben noch vor dem Flüggewerden. Anders als beim Flügelwachstum ähnelten sich die Wachstumsraten der Tarsen in der ersten Entwicklungsphase im Nest bei allen Geschwistern. Während der zweiten Entwicklungsphase im Nest wiesen die Wachstumsraten beider bewegungsrelevanten Merkmale, - Tarsen- und Flügellängen, das gleiche Muster auf, d. h. bei den später geschlüpften Küken gab es höhere Werte als bei den früher geschlüpften. In der zweiten Entwicklungsphase wirkte sich Regen, aber nicht die Temperatur, negativ auf das Wachstum aus. Unsere Ergebnisse zeigen, dass die Wachstumsmuster zwischen den Nestbewohnern unterschiedlich waren, was sich am deutlichsten in der Geschwindigkeit des Flügelwachstums zeigte. Diese Untersuchung verbessert unser Wissen über Gelegeverkleinerung und Kainismus bei Greifvögeln.

\section{Introduction}

Growth and early development have been shown to have longterm consequences for survival and fitness in a variety of taxa (Gotthard 2001; Metcalfe and Monaghan 2001; Lummaa and Clutton-Brock 2002), including birds (Richner et al. 1989; Lindström 1999; Mainwaring and Hartley 2012; Remeš and Matysioková 2016). The post-natal growth rates of altricial terrestrial birds are among the fastest of all vertebrates (Case 1978). Because of its survival advantages, growth rate is an important trait in the life-history strategy of avian ontogeny and is subject to strong directional selection (Dmitriew 2011). Highly variable patterns of avian post-natal growth are influenced by an array of extrinsic and intrinsic factors. The most important extrinsic factors which explain growth patterns include environmental conditions, such as food availability (Emlen et al. 1991; Tremblay et al. 2005; Mccarty and Winkler 2008), weather (Mccarty and Winkler 2008; Mainwaring and Hartley 2016; Morganti et al. 2017) and latitude (Benharzallah et al. 2015; Remeš et al. 2020). Among the weather factors, ambient temperature, windspeed and precipitation can influence nestling growth (Konarzewski and Taylor 1989; Dawson et al. 2005; Salaberria et al. 2013; Kasprzykowski et al. 2014; Sauve et al. 2021). During periods of adverse weather, access to food resources is often impeded by the limited foraging efficiency of adult birds, which, in turn, negatively affects the rates of both provisioning and nestling growth (Cox et al. 2019). On the other hand, the intrinsic factors that influence nestling growth include maternally induced effects in relation to the species' reproductive biology, such as hatching asynchrony (Mainwaring et al. 2009), clutch size and the extent of parental care (Kasprzykowski et al. 2014). Asynchronous hatching leads to intra-brood size hierarchy, and sibling competition is thought to exert a strong selective pressure on growth in many bird species (Ricklefs 1982; Nilsson and Svensson 1996; Mainwaring et al. 2010). The resulting age and size disparities frequently offer significant growth and survival advantages to the larger siblings. Sibling rivalry, especially among raptor broods, varies with the size hierarchies created by hatching asynchrony, and its consequences are often the poor growth and high mortality of the youngest nestling (Morandini and Ferrer 2015). Although the poor growth of the youngest nestlings in a brood has been well documented, only a few empirical studies have investigated whether and how hatching asynchrony affects growth patterns of different body traits during growth between nestlings (Kasprzykowski et al. 2014; Hildebrandt and Schaub 2018), especially in raptors (Donázar and Ceballos 1989; Krijgsveld et al. 1998).

In this study, we investigated the rate of wing and tarsus growth in nestlings of Marsh Harrier Circus aeruginosus in relation to intrinsic and extrinsic factors during two consecutive subperiods of the nestling phase. The main idea of the study was to: (1) investigate how nestlings differ from one another in their developmental pattern, depending on their hatching order and brood size, (2) determine how growth patterns of nestlings respond to local climatic conditions, and (3) investigate variation of nestling growth patterns during two subperiods of nestling rearing. We hypothesized that brood size, hatching order and weather conditions would affect growth rates, although we expected that the biological factors would have a greater impact on the growth rate of nestlings than the meteorological parameters (see Kasprzykowski et al. 2014). Marsh Harrier is a species with obligatory cainism, so brood reduction occurs in most nests as a result of siblicide, and the youngest nestling is killed by older, dominant nestmates. Partial brood losses occur at a level of ca 1.5 nestling per successful brood and usually only three nestlings fledge from a complete clutch of five eggs (Witkowski 1989). We, therefore, focused on finding out how growth patterns in nestlings of different rank change as a result of strong competition between nestmates across two subperiods of nestling rearing and which biometric trait exhibits the greatest variation. In the context of climate change, it is also important to study the effects of local weather conditions on the evolution of nestling growth traits (Sauve et al. 2021). Understanding the growth patterns of body components in relation to birds of prey biology may lead to a better understanding of the life-history strategy of species with brood reduction and their adaptation to variable ecological conditions. 


\section{Materials and methods}

\section{Study system}

The study was conducted over six breeding seasons (2007, 2008, 2009, 2011, 2018 and 2019) in the agricultural landscape of eastern Poland on four fishpond complexes: Siedlce, Rudka, Szostek and Moscibrody $\left(52^{\circ} 05^{\prime}-52^{\circ} 11^{\prime} \mathrm{N}\right.$, $21^{\circ} 58^{\prime}-22^{\circ} 18^{\prime} \mathrm{E}$ ), all of which are used mainly for the commercial breeding of Common Carp Cyprinus carpio. The ponds varied in area from 65 to 203 ha, and the total area of all four was $443 \mathrm{ha}$. Most of the ponds were partially covered by tall marsh vegetation consisting of Bulrush (Common Reedmace) Typha latifolia, Common Reed Phragmites australis and Sedges Carex spp., creating a suitable breeding habitat for Marsh Harriers. The study species is longdistance migrant that builds its nests on the ground in tall reedbeds. Marsh Harriers rear only one brood per year and female lay 2-8 eggs in a clutch, with an average of 5.0 eggs. Incubation lasts for 30-36 days and nestlings start to fly after 37-44 days (Witkowski 1989). Eggs are laid at 2-day intervals, and this can lead to significant differences in the size hierarchy. The last-hatched nestlings in broods of five suffering a strong competitive disadvantage compared to their older siblings. Marsh Harriers are sexually dimorphic in size and also exhibit pronounced sexual dimorphism in their adult plumage (Simmons and Simmons 2000).

\section{Field procedures}

To locate active nests, each study pond was visited at intervals of 1-3 days between mid-April and mid-May. The birds were observed carrying nest material to the emergent vegetation belt and during aerial food-passes near their potential nest site. Having identified a potential nest site, the observers inspected the vegetation belt on foot along fixed line transects. Once located, the nests were numbered and their positions recorded on a GPS device. A total of 66 nests ( 3 in 2007, 18 in 2008, 14 in 2009, 19 in 2011, 4 in 2018 and 8 in 2019) in the study area were visited at intervals of 5-7 days during the nestling period. After hatching, the chicks were marked with coloured plastic rings to allow individual identification; these were subsequently removed just before they fledged. During each visit, the number of nestlings was noted, and biometric measurements of each nestling were made, including the wing and tarsus lengths. Wing lengths were measured on the folded wing from the carpal joint to the tip using a ruler accurate to the nearest $1 \mathrm{~mm}$, while tarsus lengths were measured using callipers $( \pm 0.1 \mathrm{~mm})$. The aim was to assess the growth rates of all hatched chicks in the two nesting subperiods. The average 6-day interval between measurements seems to best fit the description of the chick growth of a medium-sized bird species (see Kasprzykowski et al. 2014). Therefore, nestlings were measured on three occasions: (1) 1 day after the last chick had hatched in the first week of a nestling's life (up to 7 days); (2) after the elapse of a mean period of 6.44 days (range 5-8 days) when it was 10-14 days; (3) after the elapse of a mean period of 6.37 days (range $4-8$ days) when it was 16-21 days. The difference in time covered by the period was not significant ( $t$ test $=0.54, p=0.585, \mathrm{df}=310$ ). In the first nestling subperiod, 11 nests with two nestlings, 17 with three nestlings, 20 with four nestlings and 4 with five nestlings were monitored. In the second subperiod, 10 broods with two nestlings, 16 with three nestlings and 14 with four nestlings were analysed. For the first subperiod, growth rates for both wing and tarsus were obtained from 173 nestlings, and for the second period from 138 nestlings. There were fewer measurements of nestlings from the second subperiod, because some did not survive to the second phase of development. Of the 66 nests, 12 were depredated before the end of second nestling subperiod, and 17 experienced partial losses, including all the last-hatched nestlings from broods of five. An average of 2.5 young fledged from the nests that were successful.

\section{Weather data}

The meteorological data were obtained from the Siedlce weather station, the nearest one to the pond complexes $\left(52^{\circ} 25^{\prime} \mathrm{N}, 22^{\circ} 26^{\prime} \mathrm{E}\right)$, with distances to the ponds ranging from 1 to $20 \mathrm{~km}$. Four weather parameters were measured for each nestling growth period: mean temperature, mean minimum temperature, mean daily precipitation $(\mathrm{mm} / \mathrm{day})$ and mean wind speed $(\mathrm{km} / \mathrm{h})$. The mean daily temperature at the beginning of the breeding period in April ranged from $8.3{ }^{\circ} \mathrm{C}$ in 2007 to $12.9{ }^{\circ} \mathrm{C}$ in 2018 , while the mean daily precipitation range was from $0.1 \mathrm{~mm}$ in 2009 to $1.5 \mathrm{~mm}$ in 2008. At the end of the breeding period in July, the mean daily temperature varied from $17.9^{\circ} \mathrm{C}$ in 2019 to $19.9^{\circ} \mathrm{C}$ in 2018 , and the mean daily precipitation range was from $1.3 \mathrm{~mm}$ in 2019 to $6.6 \mathrm{~mm}$ in 2011 .

\section{Statistical analyses}

In accordance with Brody (1945) and You et al. (2009), we calculated the relative growth rate (RGR) for each individual nestling as

$\mathrm{RGR}=\left[\left(\ln W_{t}-\ln W_{0}\right) / t\right] \times 100(\%)$,

where $W_{0}$ and $W_{t}$-the respective biometric measurements taken at the beginning and the end of the growth period $t$ (days). This yielded the daily wing length increments, expressed as the percentages of the initial values in the two 
periods of nestling growth between the first and second, and between the second and third weeks of life. The analysis focused on seven possible predictors of RGR for Marsh Harrier nestlings: (1) brood size, estimated as the number of live nestlings in the nest; (2) hatching order of nestlings within the brood, labelled 1, 2, 3, 4 and 5; (3) the first and second nestling subperiods; (4) mean daily precipitation (hereafter rainfall) during the time window $(\mathrm{mm} /$ day) between two consecutive measurements of a nestling; (5) mean wind speed $(\mathrm{km} / \mathrm{h}) ;(6)$ mean temperature $\left({ }^{\circ} \mathrm{C}\right)$ during the same time and (7) mean minimum temperature $\left({ }^{\circ} \mathrm{C}\right)$. Originally, we analysed four weather parameters during the period of measured nestling growth-temperature, rainfall, minimum temperature and wind speed. Variation in these variables was summarized by principal component scores, acquired from principal component analysis, to obtain predictors free from multicollinearity problems. Here, the first principal component reflected mostly the contrast between rainfall (loading 0.32 ) and mean temperature (loading - 0.70). Therefore, we decided to include only mean temperature and rainfall in the models (Table S1).

All statistical analyses were performed using RStudio ( R Core Team 2020). The possible effect of predictors on the growth rate of Marsh Harrier nestlings was analysed using an information theoretic approach (Burnham and Anderson 2002). Multiple competing models were assessed with regard to their fit to the data using AIC as the leading criterion. Linear mixed models (LMM) with Gaussian family and identity link function were employed to analyse the relationship between the daily RGRs of the response variables (wing and tarsus length) and the seven predictors. The main predictors were considered fixed factors, while nest identity nested within year was further introduced as a random factor. Following Zuur et al. (2009), we identified the optimal structure of the random component of our candidate models, by comparing models with the same beyond-optimal structure of fixed effects but differing in their random effects. For wing increments, the model with nest identity nested within year performed better $(\mathrm{AIC}=849.49)$ than the model with no random component (AIC $=865.14$ ) or a random component including year only ( $\mathrm{AIC}=880.42)$. By calculating and comparing the AIC scores of several possible interaction terms between predictors, we identified the final structure of the global model: this included an interaction term between nestling subperiod and rainfall as well as interaction between nestling subperiod and hatching order (AIC $=788.42)$. The global model for the relative growth rate of wing length was thus: RGR brood size + nestling subperiod*rainfall + nestling subperiod*hatching order + temperature + (1lyear/nest).

We applied the same approach to the construction of models for tarsus increments: models with a random effect of nest identity nested within year performed better $(\mathrm{AIC}=582.27)$ than those with no random component
$(\mathrm{AIC}=662.56)$ or those including only the random effect of year (AIC $=678.50)$. Log-likelihood ratio test was used to confirm the significance of random effect nest identity nested within year. The subsequent analyses thus included nest (brood) identity nested within year as a random effect. The global model also contained an interaction term between nestling subperiod and rainfall as well as interaction between nesting subperiod and hatching order $(\mathrm{AIC}=558.35)$ in the LMM component. The global model for the relative tarsus growth rate was thus the same as for wing growth: RGR brood size + hatching order*nestling subperiod + nestling subperiod*rainfall + temperature + (1lyear/ nest). Brood size, hatching order and nestling subperiod were formatted as factorial variables, while rainfall and temperature were numerical variables. Using the MuMIn package we calculated AICc for all possible subsets of the global model (Bartoń 2020), and using model averaging based on an information criterion, we calculated a set of models that fell within the $95 \%$ confidence limits. Pseudo- $R^{2}$ for the LMM was computed following Nakagawa and Schielzeth (2013), as implemented in the MuMIn package. The lsmeans package was used to extract least-squares means and $95 \%$ confidence limits for all categorical effects (Lenth 2016). Differences in wing and tarsus growth rates between hatching order categories were checked in separate analyses using Tukey's post-hoc test. The assumptions of normally distributed residuals and deviations in homoscedasticity were checked using the $\mathrm{R}$ package redres (Goode 2019).

\section{Results}

To determine the relative importance of variables, we summed the Akaike weights of all the models containing a focal predictor across the entire set of 52 competing models. According to Burnham and Anderson (2000), the higher the combined weight for an explanatory variable, the more important it is for the analysis. Modelling of the factors

Table 1 Relative importance of predictor variables for models of wing and tarsus relative growth rate increments

\begin{tabular}{lll}
\hline Variable & Wing & Tarsus \\
\hline Hatching order & 1.00 & 1.00 \\
Nestling subperiod & 1.00 & 1.00 \\
Nestling subperiod*hatching order & 1.00 & 1.00 \\
Rainfall & 0.58 & 0.94 \\
Nestling subperiod*rainfall & 0.42 & 0.91 \\
Temperature & 0.30 & 0.32 \\
Brood size & 0.13 & 0.21 \\
\hline
\end{tabular}

For each response variable, the importance of the summed Akaike weights of all models containing the focal predictor was calculated across the entire set of 52 competing models 
influencing variation in daily wing length gain revealed that the importance of hatching order and nestling subperiod as well as its interaction were the highest, followed by rainfall, and the interaction between nestling subperiod and rainfall. In contrast, the importance of temperature and brood size was low (Table 1). The 95\% confidence model set included seven models (Table 2), five of which were within $\Delta \mathrm{AICc}<2$ in the candidate model set. The best model for daily wing length increments included hatching order, nestling subperiod, rainfall, nestling subperiod-rainfall and nestling subperiod-hatching order interaction (Table 3). The best model explained $66 \%$ of the variation in the relative wing length gain rate, as estimated by pseudo- $R^{2}$ statistics for LMM. In the first subperiod of nestling life, wing length increments averaged $4.99 \% /$ day, with extensive variation between individual nestlings (IQR: 4.48-5.63). Hatching order affected growth rate in such a way that wing growth in the fifth, last-hatched nestlings was slower than in their siblings (Tukey post-hoc test, $p<0.012$ for four comparisons, Fig. 1A). There were also differences in growth rate between the fourth nestling and other hatching categories (Tukey post-hoc test, $p<0.012$ for four comparisons). The first, second and third nestlings grew at the same rate (Tukey post-hoc test, $p>0.238$ for three comparisons). In the second subperiod of nestling development, wing length increments were smaller than in the first period, on average $3.45 \% /$ day (IQR: 2.72-4.15). Unexpectedly, the hatching order affected growth rates in the second subperiod of life inversely in comparison with the wing growth of young nestlings in the first developmental subperiod (Fig. 1B). The rate of growth in the second nestling subperiod was significantly faster in the fourth nestlings than in the first and second ones (Tukey post-hoc test, $p<0.001$ for two comparisons). Differences were also found between the third nestling and its two older siblings (Tukey post-hoc test, $p<0.006$ for two comparisons), but not between the first and second ones (Tukey posthoc test, $p=0.465$ ). In the first nestling subperiod, rainfall did not significantly affect wing growth, whereas it had a significant negative effect in the second subperiod (Fig. 2; Table 3).

As regards daily tarsus length increments, the importance of hatching order, nestling subperiod, rainfall as well as interaction between nestling subperiod and hatching order was the greatest, followed by the nestling subperiod-rainfall interaction and temperature, whereas that of brood size was lowest (Table 1). Five models included the $95 \%$ confidence model set (Table 2). The best model for daily tarsus length increments included hatching order, nestling subperiod and rainfall, as well as the nestling subperiod-rainfall and nestling subperiod-hatching

Table 2 Results of seven models for wing relative growth rate and five models of tarsus relative growth rate; these make up the selected 95\% confidence set

\begin{tabular}{|c|c|c|c|c|c|}
\hline Model (fixed effects) & df & LL & $\mathrm{AICc}$ & $\triangle \mathrm{AICc}$ & AICcwt \\
\hline \multicolumn{6}{|l|}{ RGR wing } \\
\hline $\begin{array}{l}\text { Intercept }+ \text { hatching order }+ \text { nestling subperiod }+ \text { nestling subperiod*rain }+ \text { nestling } \\
\text { subperiod*hatching order }+ \text { rain }\end{array}$ & 14 & -377.875 & 785.2 & 0.00 & 0.281 \\
\hline Intercept + hatching order + nestling subperiod + nestling subperiod*hatching order & 12 & -380.077 & 785.2 & 0.01 & 0.279 \\
\hline Intercept + hatching order + nestling subperiod + nestling subperiod*hatching order + temp & 13 & -379.793 & 786.9 & 1.63 & 0.124 \\
\hline $\begin{array}{l}\text { Intercept }+ \text { hatching order }+ \text { nestling subperiod }+ \text { nestling subperiod*rain }+ \text { nestling } \\
\text { subperiod*hatching order }+ \text { temp }+ \text { rain }\end{array}$ & 15 & -377.655 & 787.0 & 1.78 & 0.115 \\
\hline Intercept + hatching order + nestling subperiod + nestling subperiod*hatching order + rain & 13 & -379.966 & 787.2 & 1.98 & 0.104 \\
\hline $\begin{array}{l}\text { Intercept }+ \text { hatching order }+ \text { nestling subperiod }+ \text { nestling subperiod*hatching order }+ \text { nestling } \\
\text { subperiod*rain + rain + brood size }\end{array}$ & 17 & -376.271 & 788.7 & 3.49 & 0.049 \\
\hline Intercept + hatching order + nestling subperiod + nestling subperiod $*$ hatching order + rain + temp & 14 & -379.653 & 788.7 & 3.49 & 0.046 \\
\hline \multicolumn{6}{|l|}{ RGR tarsus } \\
\hline $\begin{array}{l}\text { Intercept }+ \text { hatching order + nestling subperiod + nestling subperiod*rain + nestling } \\
\text { subperiod*hatching order + rain }\end{array}$ & 14 & -263.735 & 557.0 & 0.00 & 0.531 \\
\hline $\begin{array}{l}\text { Intercept }+ \text { hatching order }+ \text { nestling subperiod + nestling subperiod*rain + nestling } \\
\text { subperiod*hatching order + temp + rain }\end{array}$ & 15 & -263.489 & 558.7 & 1.72 & 0.224 \\
\hline $\begin{array}{l}\text { Intercept }+ \text { hatching order }+ \text { nestling subperiod + nestling subperiod*rain + nestling } \\
\text { subperiod*hatching order + brood size + rain }\end{array}$ & 17 & -261.753 & 559.7 & 2.74 & 0.135 \\
\hline $\begin{array}{l}\text { Intercept }+ \text { hatching order }+ \text { nestling subperiod }+ \text { nestling subperiod } * \text { hatching order }+ \text { nestling } \\
\text { subperiod*rain }+ \text { brood size }+ \text { rain }+ \text { temp }\end{array}$ & 18 & -261.179 & 560.8 & 3.86 & 0.077 \\
\hline Intercept + hatching order + nestling subperiod + nestling subperiod*hatching order & 12 & -268.698 & 562.5 & 5.54 & 0.033 \\
\hline
\end{tabular}

$d f$ degrees of freedom, $L L$ model log-likelihood, AICC corrected AIC criterion, $\triangle A I C c$ the difference between AICc of the focal model and the best model in the data set, AICcwt the weight for the model 
Table 3 Estimated model coefficients for the best LMM model of wing relative growth rate and tarsus relative growth rate increments

\begin{tabular}{|c|c|c|c|c|c|c|}
\hline \multirow[t]{2}{*}{ Fixed effects } & \multicolumn{3}{|c|}{ RGR wing } & \multicolumn{3}{|c|}{ RGR tarsus } \\
\hline & Estimate & SE & $p$ value & Estimate & SE & $p$ value \\
\hline Intercept & 5.195 & 0.185 & $<0.001$ & 3.836 & 0.132 & $<0.001$ \\
\hline Hatching order 2 & -0.051 & 0.152 & 0.739 & 0.210 & 0.095 & 0.027 \\
\hline Hatching order 3 & -0.296 & 0.163 & 0.071 & 0.451 & 0.102 & $<0.001$ \\
\hline Hatching order 4 & -1.052 & 0.196 & $<0.001$ & 0.369 & 0.124 & 0.003 \\
\hline Hatching order 5 & -2.574 & 0.424 & $<0.001$ & -0.187 & 0.270 & 0.489 \\
\hline Nestling subperiod: second & -1.708 & 0.382 & $<0.001$ & -1.658 & 0.260 & $<0.001$ \\
\hline Rainfall & 0.024 & 0.037 & 0.518 & -0.023 & 0.026 & 0.382 \\
\hline Nestling subperiod: second*rainfall & -0.414 & 0.200 & 0.040 & -0.413 & 0.137 & 0.002 \\
\hline Hatching order $2 *$ nestling subperiod: second & 0.335 & 0.230 & 0.147 & -0.015 & 0.144 & 0.915 \\
\hline Hatch order $3 *$ nestling subperiod: second & 1.245 & 0.249 & $<0.001$ & 0.248 & 0.156 & 0.115 \\
\hline Hatch order $4 *$ nestling subperiod: second & 2.418 & 0.313 & $<0.001$ & 0.884 & 0.197 & $<0.001$ \\
\hline Random effects & Variance & SD & $p$ value & Variance & SD & $p$ value \\
\hline Nest: year & 0.189 & 0.435 & $<0.001$ & 0.242 & 0.492 & $<0.001$ \\
\hline Year & 0.043 & 0.208 & 0.152 & 0.015 & 0.122 & 0.337 \\
\hline Residual & 0.601 & 0.775 & & 0.235 & 0.485 & \\
\hline
\end{tabular}

For fixed effects, standard errors (SE) and $p$ values are shown. For random effects, the values are variance estimates and their standard deviations (SD)

order interaction (Table 3). Best model explained 86\% of the variation in the relative tarsus length gain rate, as estimated by pseudo- $R^{2}$ statistics for LMM. Tarsus length increments averaged $3.90 \%$ /day in the first subperiod of life, with extensive variation between individual nestlings (IQR: 3.39-4.47). In contrast to wing growth, all nestlings had similar growth rates, and no differences between any of the hatching order categories were found (Tukey posthoc test, $p>0.072$ for ten comparisons, Fig. 3A). In the second subperiod of nestling development, tarsus length increments were smaller than in the first subperiod, averaging $1.81 \% /$ day (IQR: 1.14-2.39). Hatching order affected tarsus growth rates in the same way as the wing growth rates (Fig. 3B). The first and second hatched nestlings grew significantly more slowly than the third and fourth ones (Tukey post-hoc test, $p<0.005$ for four comparisons). No differences were found between the two oldest nestlings (Tukey post-hoc test, $p=0.524$ ) or between the two youngest ones (Tukey post-hoc test, $p=0.288$ ). As in the case of wing growth, tarsus growth rates were negatively influenced by rainfall in the second life subperiod (Fig. 4).

\section{Discussion}

Our study showed that overall growth rates were achieved faster in the first subperiod of nestling life than in the second one. The wing growth rate was slower in fourth- and fifth-hatched nestlings (Fig. 1A), whereas the tarsus growth rate pattern did not differ significantly between nestlings (Fig. 3A). During the critical growing phase, when younger nestlings are at the greatest risk of brood reduction, the growth rate of wings is not a prioritized trait. This mode of development at the beginning of nestling life can be explained by individual growth strategies. Studies across species show that competition within the nest can have a strong effect on the growth strategies of nestlings. Nestlings may selectively divert resources to body structures and functions that are the most essential for survival and effective nest-mate competition (Gil et al. 2008; Mainwaring et al. 2009, 2010; Hildebrandt and Schaub 2018). Chicks may benefit by slowing the growth rates of some body parts to reduce energy costs but also to protect the growth of those body structures most useful in competing with nest mates (Starck and Ricklefs 1998).

We recorded overall slower growth rates during the second developmental subperiod than in the first one. However, we did record faster growth rates of both locomotor traits in later-hatched Marsh Harrier (third and fourth) chicks than in the earlier ones (Figs. 1B, 3B). Wing growth at this point may be a priority for two reasons. First, fast wing growth can be explained by the need to leave the nest as quickly as possible. In other bird species, the rapid growth of wings in later-hatched chicks allows them to leave the nest as soon as possible (Nilsson and Svensson 1996; Mainwaring et al. 2010), which increases their chances of survival under high 
pressure from predators (Remeŝ and Martin 2002; Cheng and Martin 2012). This could also apply to Marsh Harrier, because in our study population, the daily nest survival rate declined with nest age (Zaremba et al. 2020). Second, Marsh Harrier is a bird of prey nesting in an aquatic environment, so the ability to fly, as well as wing and feather development, may be crucial for the survival of nestlings during the critical transition when leaving the nest (Simmons and Simmons 2000). As Marsh Harrier is not so well adapted to nesting in an aquatic environment as other waterbirds (see Kasprzykowski et al. 2014), fledglings leaving the nest with underdeveloped wings could be at risk of drowning.

Although Marsh Harrier exhibits pronounced size dimorphism between the sexes, this should not be a confounding factor, at least for the wing growth rates in our analysis. According to Krijgsveld et al. (1998), the average wing length of 51-day-old females was only 1.05 times that of males, and the difference in wing growth between the sexes was not significant at any age. Witkowski (1989) wrote that there were some differences in tarsus length between males and females but that they were not detectable until after the nestlings were 18 days, so this could have been a confounding factor only in the second subperiod of growth. In this case, we assumed that the brood sex ratio was close to parity and was equally represented in each category.

Overall, faster growth rates of later-hatched nestlings have been recorded in other species with hatching asynchrony, such as Bittern Botaurus stellaris, which nests in the same biotope as Marsh Harrier (Kasprzykowski et al. 2014). Consequently, the faster growth rates of younger Marsh Harrier nestlings enable them to "catch up" with their earlierhatched siblings, which causes reduced size hierarchy before fledging. Such a developmental strategy could cancel out the negative effects of hatching asynchrony and enhance the survival chances of later-hatched chicks by maximizing sizerelated fitness benefits prior to fledging (Jones et al. 2017).

Only rainfall among the weather factors modelled had an adverse effect on the second nestling subperiod (Figs. 2, 4). This is despite the fact that more rainfall occurred in the first subperiod. A possible explanation is that females stay with the nestlings during their first days of life to protect them from the poor weather (Witkowski 1989). On the other hand, the brood's food demands are usually greater in the
Fig. 1 Variation of wing relative growth rate in the first (A) and the second nestling subperiod (B) in Marsh Harrier nestlings in relation to hatching order. Modelled means $\pm 95 \%$ confidence limits for the best model selected are shown. Values extracted using the lsmeans $\mathrm{R}$ package. Differences in mean value of growth rates were checked using Tukey post-hoc test and are showed by different letters $(\mathrm{a}, \mathrm{b}$ and $\mathrm{c})$
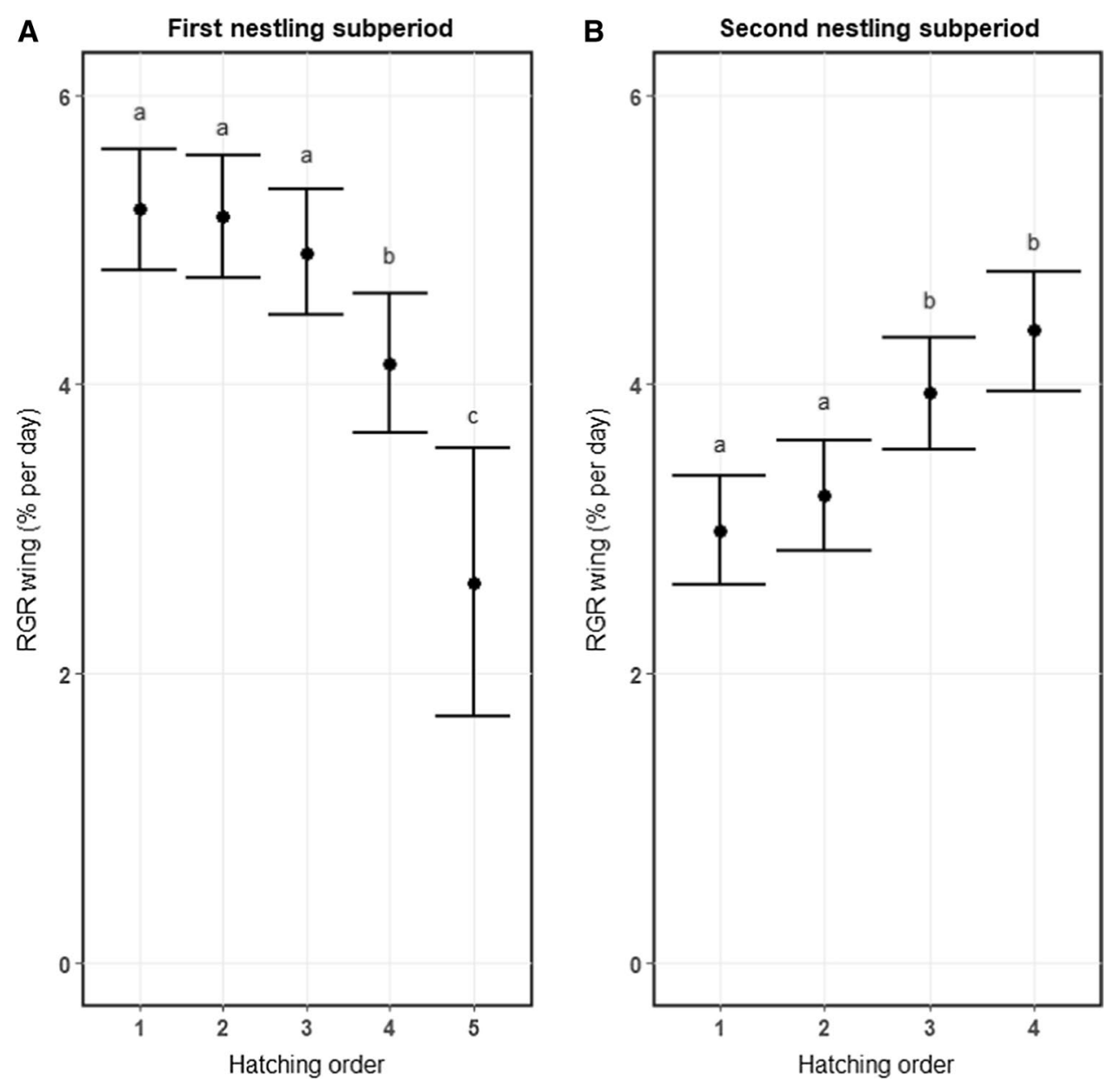


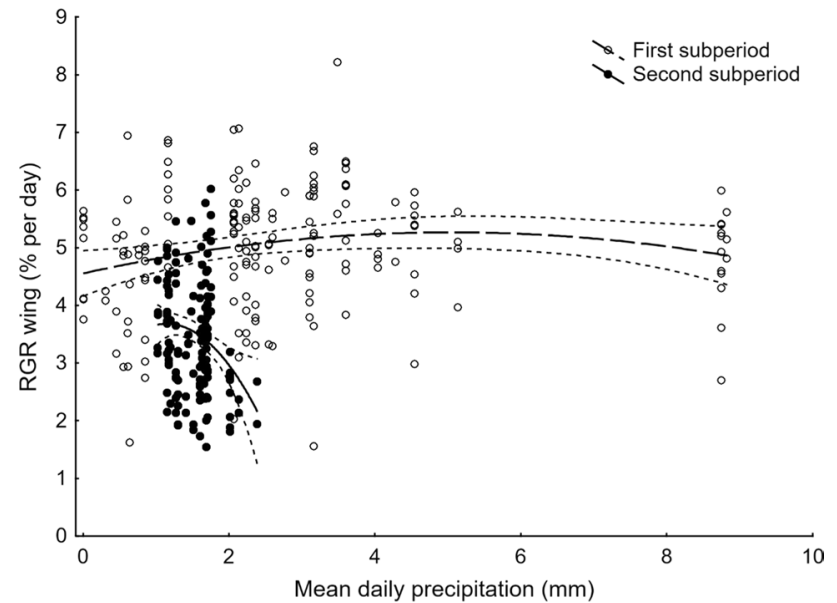

Fig. 2 Relationship between wing relative growth rate and mean daily precipitation in the first and the second nestling subperiod in Marsh Harrier nestlings

later nestling phase. The energy costs of the growth rate may not be satisfied if neither parent can find sufficient food during periods of heavy rainfall. Spells of inclement weather can affect growth rates either directly by chilling or indirectly by limiting the foraging time available to adults, which may result in food shortages for the nestlings (Dawson and Bortolotti 2000; Sergio 2003), and in turn, will affect their growth rates (Kasprzykowski et al. 2014). Although rainfall has an adverse effect on nestling growth rates, Kryński et al. (2016) demonstrated that the weather conditions in our study population did not appear to cause brood reduction in Marsh Harrier.

We did not detect any influence of brood size on tarsus and wing growth rates in our study. This is surprising, as we expected larger broods to grow more slowly owing to the probably higher nestmate competition. However, the lack of a relationship between brood size and growth rate had been noted earlier in other species (Platteeuw et al. 1995; Geiser et al. 2008). This may indicate that adult birds adjust the number of eggs in relation to territory capacity and their own abilities and experience in such a way that an optimal clutch size is achieved.
Fig. 3 Variation in tarsus relative growth rate in the first (A) and the second nestling subperiod (B) in Marsh Harrier nestlings in relation to hatching order. Modelled means $\pm 95 \%$ confidence limits for the best model selected are shown. Values extracted using the lsmeans $\mathrm{R}$ package. Differences in mean value of growth rates were checked using Tukey post-hoc test and are showed by different letters ( $\mathrm{a}$ and $\mathrm{b}$ )
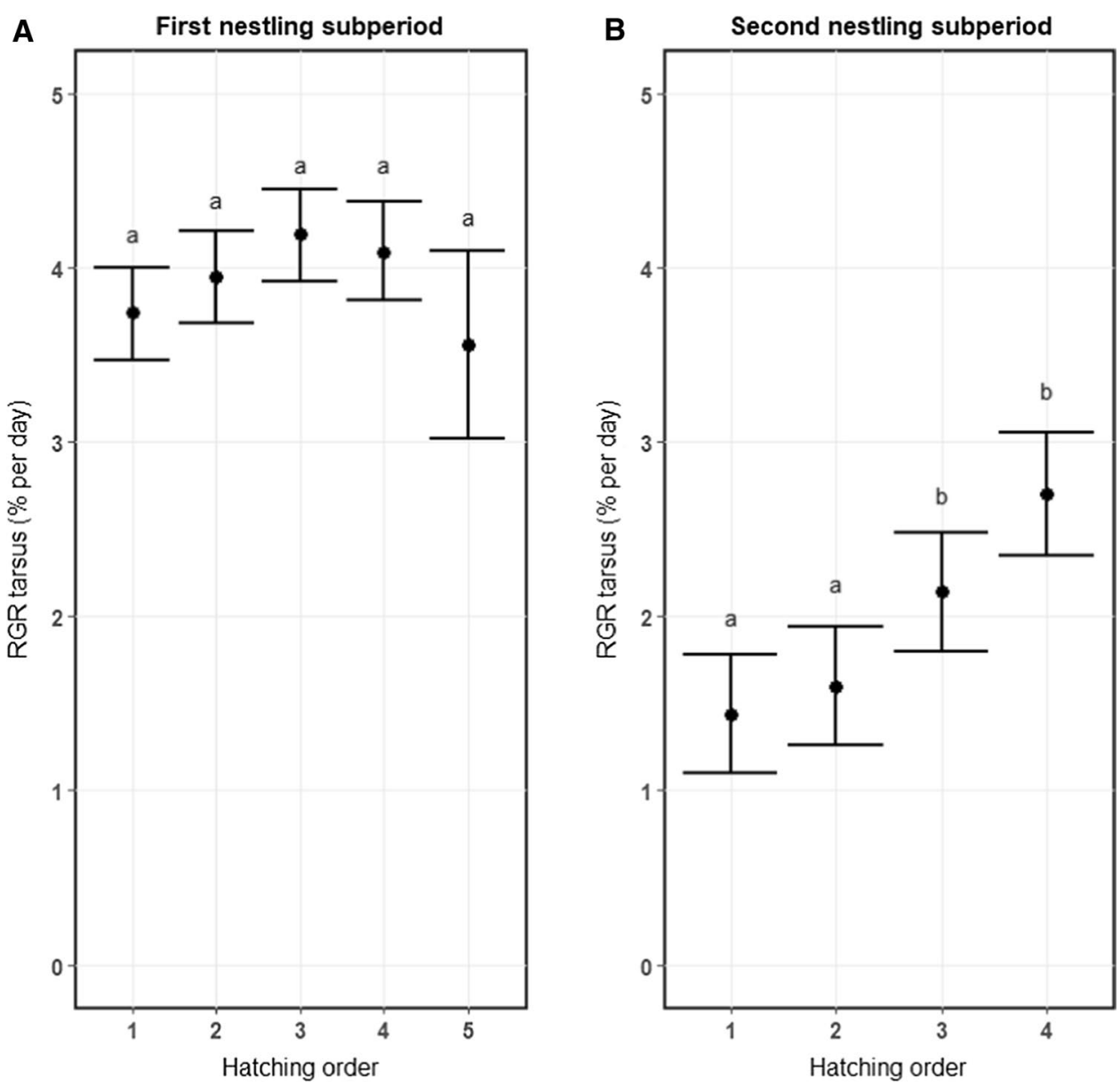


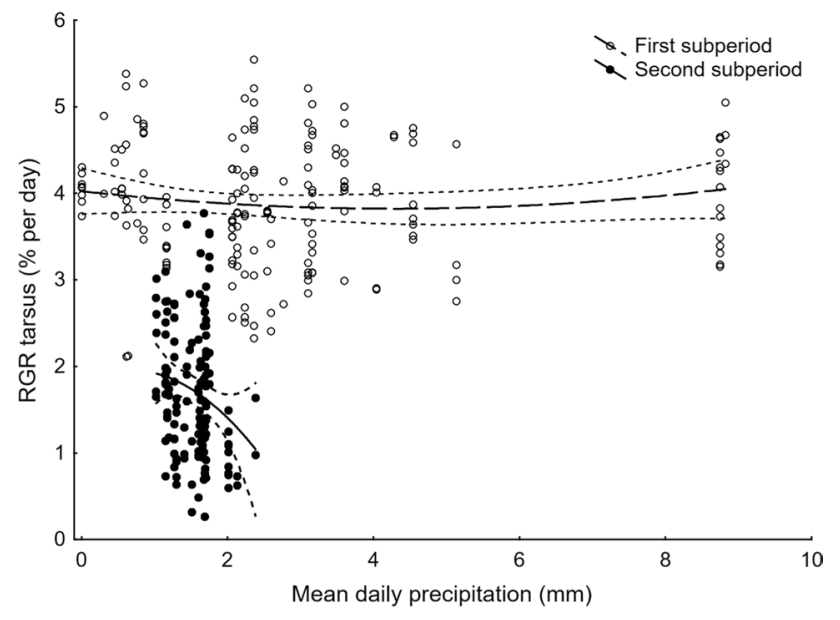

Fig. 4 Relationship between tarsus relative growth rate and mean daily precipitation in the first and the second nestling subperiod in Marsh Harrier nestlings

\section{Conclusion}

Developmental rates of locomotor traits throughout the nestling rearing process in Marsh Harrier are mostly affected by the hatching order and the nestling subperiod but not brood size. Younger nestlings, which are exposed to a greater risk of brood reduction, displayed significant variation in growth patterns compared to their older siblings; this was most evident in the rate of wing growth in fourth- and fifth-hatched nestlings. In the second subperiod of development, rainfall depressed both wing and tarsus growth rates in all nestlings. Our results support the existence of differences in developmental rates between nestlings and help to understand the phenomenon of brood reduction in birds of prey. Further studies are needed to examine the growth hierarchy of the response of different morphological traits to hatching rank and developmental stage to better understand intrabrood growth strategies.

Supplementary Information The online version contains supplementary material available at https://doi.org/10.1007/s10336-022-01968-3.

Acknowledgements We are grateful to Karol Bosek, Rafał Kuropieska, Daniel Paczóski, Marta Szaniawska, Kamil Kryński, Tomasz Pietrzak, Paweł Radzikowski, Monika Budzyńska and Cezary Sadowy for their help in carrying out the fieldwork. We would like also thank Marcin K. Dyderski for help with the statistical analyses and two anonymous reviewers for their detailed reviews that helped improve quality of the manuscript.

Author contributions UZ collected and analysed the data, wrote the manuscript and reviewed drafts of the paper. ZK conceived and designed the experiments, authored drafts of the paper and approved the final draft. AG collected the data, reviewed drafts of the paper and approved the final draft.

Funding The study has been supported by Siedlce University of Natural Sciences and Humanities.
Data availability Data are available in the figshare Repository https:// figshare.com/s/90329d263c5c955726cd.

Code availability Code is available in the figshare Repository https:// figshare.com/s/e71418716f76c98683fd.

\section{Declarations}

Conflict of interest The corresponding author declares on behalf of authors that there is no conflict of interest to disclose.

Ethical approval All operations were conducted under the programme 'Research of birds in the disclimax ecosystems' approved by the Institute of Biological Sciences, Siedlce University of Natural Sciences and Humanities (number of approval: IB.5030.8.2018). The study fulfilled the current Polish Law and was permitted by Ministry of the Environment (approval number: 425/2019) and Regional Directorate for Environmental Protection in Warsaw allowed for this research project by the letter (number of approval: WSTS.6401.34.2018.MO).

Consent to participate Not applicable.

Consent for publication Not applicable.

Open Access This article is licensed under a Creative Commons Attribution 4.0 International License, which permits use, sharing, adaptation, distribution and reproduction in any medium or format, as long as you give appropriate credit to the original author(s) and the source, provide a link to the Creative Commons licence, and indicate if changes were made. The images or other third party material in this article are included in the article's Creative Commons licence, unless indicated otherwise in a credit line to the material. If material is not included in the article's Creative Commons licence and your intended use is not permitted by statutory regulation or exceeds the permitted use, you will need to obtain permission directly from the copyright holder. To view a copy of this licence, visit http://creativecommons.org/licenses/by/4.0/.

\section{References}

Bartoń K (2020) MuMIn: multi-model inference. R package version 1.43.17. https://cran.r-project.org/web/packages/MuMIn. Accessed 15 Apr 2020

Benharzallah N, Si Bachir A, Taleb F, Barbraud C (2015) Factors affecting growth parameters of White Stork nestlings in eastern Algeria. J Ornithol 156:601-612. https://doi.org/10.1007/ s10336-015-1162-0

Brody S (1945) Bioenergetics and growth, with special reference to the efficiency of domestic animals. Reinhold, New York

Burnham KP, Anderson DR (2002) Model selection and multimodel inference. Springer, Heidelberg

Case TJ (1978) On the evolution and adaptive significance of postnatal growth rates in the terrestrial vertebrates. Q Rev Biol 53:243-282. https://doi.org/10.1086/410622

Cheng YR, Martin TE (2012) Nest predation risk and growth strategies of passerine species: grow fast or develop traits to escape risk? Am Nat 180:285-295. https://doi.org/10.1086/667214

Cox AR, Robertson RJ, Lendvai AZ, Everitt K, Bonier F (2019) Rainy springs linked to poor nestling growth in a declining avian aerial insectivore (Tachycinetabicolor). Proc R Soc B. https://doi.org/ 10.1098/rspb.2019.0018 
Dawson RD, Bortolotti GR (2000) Reproductive success of American Kestrels: the role of prey abundance and weather. Condor 102:814-822. https://doi.org/10.1093/condor/102.4.814

Dawson RD, Lawrie CC, O'Brien EL (2005) The importance of microclimate variation in determining size, growth and survival of avian offspring: experimental evidence from a cavity nesting passerine. Oecologia 144:499-507. https://doi.org/10.1007/ s00442-005-0075-7

Dmitriew CM (2011) The evolution of growth trajectories: what limits growth rate? Biol Rev 86:97-116. https://doi.org/10.1111/j.1469185X.2010.00136.X

Donázar J, Ceballos O (1989) Growth rates of nestling Egyptian Vultures Neophron percnopterus in relation to brood size, hatching order and environmental factors. Ardea 77:217-226

Emlen ST, Wrege PH, Demong NJ, Hegner RE (1991) Flexible growth rates in nestling White-fronted Bee-eaters: a possible adaptation to short-term food shortage. Condor 93:591-597. https://doi.org/ $10.2307 / 1368191$

Geiser S, Arlettaz R, Schaub M (2008) Impact of weather variation on feeding behaviour, nestling growth and brood survival in Wrynecks Jynx torquilla. J Ornithol 149:597-606. https://doi.org/10. 1007/s10336-008-0305-y

Gil D, Bulmer E, Celis P, López-Rull I (2008) Adaptive developmental plasticity in growing nestlings: Sibling competition induces differential gape growth. Proc R Soc B 275:549-554. https://doi.org/ 10.1098/rspb.2007.1360

Goode K (2019) Redres. R package version 0.0.0.9. https://github.com/ goodekat/redres.git. Accessed 19 May 2019

Gotthard K (2001) Growth strategies of ectothermic animals in temperate environments. Environment and animal development. In: Atkinson D, Thorndyke M (eds) Environment and animal development. BIOS Scientific Publishers, Oxford, pp 287-304

Hildebrandt B, Schaub M (2018) The effects of hatching asynchrony on growth and mortality patterns in Eurasian Hoopoe Upupa epops nestlings. Ibis 160:145-157. https://doi.org/10.1111/ibi.12529

Jones T, Ward M, Benson T, Brawn J (2017) Variation in nestling body condition and wing development predict cause-specific mortality in fledgling dickcissels. J Avian Biol 48:439-447. https://doi.org/ 10.1111/jav.01143

Kasprzykowski Z, Polak M, Chylarecki P (2014) Effects of weather conditions, time of breeding, brood size and hatching order on Eurasian bittern nestling growth in a food-rich fishpond habitat. Ann Zool Fenn 51:477-487. https://doi.org/10.5735/086.051.0602

Konarzewski M, Taylor J (1989) The influence of weather conditions on growth of Little Auk Alle alle chicks. Ornis Scand 20:112-116. https://doi.org/10.2307/3676877

Krijgsveld K, Dijkstra C, Visser G, Daan S (1998) Energy requirements for growth in relation to sexual size dimorphism in Marsh Harrier Circus aeruginosus Nestlings. Physiol Zool 71:693-702. https://doi. org/10.1086/515983

Kryński K, Goławski A, Kasprzykowski Z (2016) Do weather factors lead to partial brood losses in the Marsh Harrier Circus aeruginosus? Ethol Ecol Evol 29:149-156. https://doi.org/10.1080/03949370. 2015.1126360

Lenth RV (2016) Least-squares means: the R package lsmeans. J Stat Softw 69:1-33

Lindström J (1999) Early development and fitness in birds and mammals. Trends Ecol Evol 14:343-348. https://doi.org/10.1016/S01695347(99)01639-0

Lummaa V, Clutton-Brock TH (2002) Early development, survival and reproduction in humans. Trends Ecol Evol 17:141-147. https://doi. org/10.1016/S0169-5347(01)02414-4

Mainwaring MC, Hartley IR (2012) Causes and consequences of differential growth in birds: a behavioral perspective. Adv Study Behav 44:225-277. https://doi.org/10.1016/B978-0-12-394288-3.00006-X
Mainwaring MC, Hartley IR (2016) Local weather conditions have complex effects on the growth of blue tit nestlings. J Therm Biol 60:12-19. https://doi.org/10.1016/j.jtherbio.2016.05.005

Mainwaring MC, Rowe LV, Kelly DJ, Grey J, Bearhop S, Hartley IR (2009) Hatching asynchrony and growth trade-offs within Barn swallow broods. Condor 111:668-674. https://doi.org/10.1525/ cond.2009.090064

Mainwaring MC, Dickens M, Hartley IR (2010) Environmental and not maternal effects determine variation in offspring phenotypes in a passerine bird. J Evol Biol 23:1302-1311. https://doi.org/10.1111/j. 1420-9101.2010.01997.x

Mccarty JP, Winkler DW (2008) Relative importance off environmental variables in determining the growth off nestling Tree Swallows Tachycinetabicolor. Ibis 141:286-296. https://doi.org/10.1111/j. 1474-919X.1999.tb07551.x

Metcalfe NB, Monaghan P (2001) Compensation for a bad start: grow now, pay later? Trends Ecol Evol 16:254-260. https://doi.org/10. 1016/S0169-5347(01)02124-3

Morandini V, Ferrer M (2015) Sibling aggression and brood reduction: a review. Ethol Ecol Evol 27:2-16. https://doi.org/10.1080/03949 370.2014.880161

Morganti M, Rubolini D, Saino N, Caprioli M, Ambrosini R (2017) Rainfall, but not temperature, negatively affects the growth of Blue Tit Cyanistes caeruleus nestlings. Bird Study 64:159-167. https://doi. org/10.1080/00063657.2017.1309006

Nakagawa S, Schielzeth H (2012) A general and simple method for obtaining $\mathrm{R}^{2}$ from generalized linear mixed-effects models. Methods Ecol Evol 4:133-142. https://doi.org/10.1111/j.2041-210x.2012. 00261.x

Nilsson JA, Svensson M (1996) Sibling competition affects nestling growth strategies in marsh tits. J Anim Ecol 65:825-836. https:// doi.org/10.2307/5680

Platteeuw M, Koffijberg K, Dubbeldam W (1995) Growth of Cormorant Phalacrocorax carbo sinensis chicks in relation to brood size, age ranking and parental fishing effort. Ardea 83:235-245

R Core Team (2020) R: a language and environment for statistical computing. R Foundation for Statistical Computing: Vienna, Austria. https://www.R-project.org/. Accessed 1 April 2020

Remeš V, Matysioková B (2016) Survival to independence in relation to pre-fledging development and latitude in songbirds across the globe. J Avian Biol 47:610-618. https://doi.org/10.1111/jav.00841

Remeš V, Matysioková B, Vrána J (2020) Adaptation and constraint shape the evolution of growth patterns in passerine birds across the globe. Front Zool. https://doi.org/10.1186/s12983-020-00377-7

Remeŝ V, Martin T (2002) Environmental influences on the evolution of growth and developmental rates in passerines. Evolution 56:25052518. https://doi.org/10.1554/0014-3820(2002)056[2505:EIOTEO] 2.0.CO;2

Richner H, Schneiter P, Stirnimann H (1989) Life-history consequences of growth rate depression: an experimental study on carrion crows (Corvus coronecorone L.). Funct Ecol 3:617-624. https://doi.org/ $10.2307 / 2389577$

Ricklefs R (1982) Some considerations on sibling competition and avian growth rates. Auk 99:141-147. https://doi.org/10.2307/4086030

Salaberria C, Celis P, López-Rull I, Gil D (2013) Effects of temperature and nest heat exposure on nestling growth, dehydration and survival in a Mediterranean hole-nesting passerine. Ibis 156:265-275. https:// doi.org/10.1111/ibi.12121

Sauve D, Friesen V, Charmantier A (2021) The effects of weather on avian growth and implications for adaptation to climate change. Front Ecol Evol 9:1-20. https://doi.org/10.3389/fevo.2021.569741

Sergio F (2003) From individual behaviour to population pattern: weather-dependent foraging and breeding performance in Black Kites. Anim Behav 66:1109-1117. https://doi.org/10.1006/anbe. 2003.2303 
Simmons R, Simmons JR (2000) Harriers of the world: their behaviour and ecology. Oxford University Press, Oxford

Starck JM, Ricklefs RE (1998) Avian growth and development. Evolution within the Altricial- Precocial spectrum. Oxford University Press, Oxford

Tremblay I, Thomas D, Blondel J, Perret P, Lambrechts M (2005) The effect of habitat quality on foraging patterns, provisioning rate and nestling growth in Corsican Blue Tits Parus caeruleus. Ibis 147:1724. https://doi.org/10.1111/j.1474-919x.2004.00312.x

Witkowski J (1989) Breeding biology and ecology of the marsh harrier Circus aeruginosus in the Barycz valley, Poland. Acta Ornithol 25:223-320

You Y, Feng J, Wang H, Wang J, Dong C, Su X, Sun H, Gao W (2009) Variation in egg size and nestling growth rate in relation to clutch size and laying sequence in great tits Parus major. Prog Nat Sci 19:427-433. https://doi.org/10.1016/j.pnsc.2008.05.035

Zaremba U, Kasprzykowski Z, Golawski A (2020) Effect of nest age and habitat variables on nest survival in Marsh Harrier (Circus aeruginosus) in a fishpond habitat. PeerJ 9(8):e9929. https://doi.org/10. 7717/peerj.9929

Zuur AF, Ieno EN, Walker NJ, Saveliev AA, Smith GM (2009) Mixed effects models and extensions in ecology with R. Springer, New York

Publisher's Note Springer Nature remains neutral with regard to jurisdictional claims in published maps and institutional affiliations. 